\title{
Sinopsis taxonómica, ecológica y etnobotánica del género Tachigali Aubl. (Leguminosae) en la región del Cusco, Perú
}

\author{
Taxonomic, ecological and ethnobotanical synopsis of the genus Tachigali \\ Aubl. (Leguminosae) in the region of Cusco, Peru
}

\section{Isau Huamantupa-Chuquimaco ${ }^{1 / 2}$, Haroldo C. Lima ${ }^{2}$, Domingos Cardoso ${ }^{3}$, Daysi Huamán de la Vega ${ }^{1}$ \& Miguel A. Luza-Victorio ${ }^{1}$}

\begin{abstract}
${ }^{1}$ Herbario CUZ, Facultad de Ciencias, Universidad Nacional San Antonio Abad del Cusco (UNSAAC). Prolongación Av. de la Cultura, 733 Cusco, Perú. andeanwayna@gmail.com ${ }^{2}$ Programa de Pós-Graduação em Botânica, Escola Nacional de Botânica Tropical, Instituto de Pesquisas Jardim Botânico de Rio de Janeiro (ENBT/JBRJ). Rua Pacheco Leão, 2040. RJ, Brasil.

${ }^{3}$ Insituto de Biologia, Universidade Federal de Bahia (UFBA). Rua Barão de Jeremoabo, s.n., Ondina, 40170-115, Salvador, Bahia, Brasil.
\end{abstract}

\section{Resumen}

Se da a conocer la sinopsis taxonómica, etnobotánica y ecológica del género Tachigali Aubl. (Leguminosae), en la región del Cusco. Los resultados revelan la presencia de nueve especies: Tachigali chrysaloides, T. guianensis, T. macbridei, T. paniculata, T. setifera, T. vasquezii y otras tres morfoespecies. Todas presentan su distribución restringida al bosque amazónico húmedo lluvioso y al bosque amazónico húmedo pre-montano. La mayoría de especies son aprovechadas para el comercio de madera y como combustible. Se propone incluir dentro de las categorías de amenaza a cuatro especies con preocupación menor (LC), tres como casi amenazada (NT) y dos como vulnerables (VU). La riqueza de este género en el Cusco es comparable a otras regiones de alta diversidad y endemismo como Loreto en Perú y el bioma de la Mata Atlántica en Brasil, que supera ampliamente en extensión territorial a la región del Cusco.

Palabras clave: Tachigali, Amazonía, Cusco, pre-montano, "inkapacay”.

\begin{abstract}
This paper presents the taxonomic, ethnobotanical, ecological synopsis of the Tachigali genus Aubl. (Leguminosae), from Cusco region in Peru. The results reveal the presence of nine species: Tachigali chrysaloides, T. guianensis, T. macbridei, T. paniculata, T. setifera, T. vasquezii and three other morpho species. All of these species are restricted and located in the low tropical rainforest and the pre-montane tropical forest areas. A great number of the above species are used for timber commerce and for fuel. It is proposed to include those species in the category of threatened species: four of them fall under the least concern (LC), three are in near threatened category (NT) and two are considered as Vulnerable (VU). The species richness of Tachigali in Cusco region is similar to other well-recognized regions for the high diversity and endemism of the genus, such as Loreto in Peru and the Brazilian Costal Atlantic Forest, which are much larger in geographical extension than the Cusco region.
\end{abstract}

Keywords: Tachigali, Amazonía, Cusco, pre-montano, "inkapacay”. 


\section{Introducción}

Tachigali Aubl. corresponde a un género neotropical y actualmente comprende cerca de 80 especies arbóreas dentro de las Leguminosae. Este género es uno de los más diversos y abundantes en varios ecosistemas tropicales: los bosques amazónicos y montanos, el cerrado, la mata atlántica y los bosques estacionalmente secos (Dwyer 1957; Lewis 2005; Silva \& Lima 2007; van der Werff 2008; Pennington et al. 2009).

Este grupo importante de árboles no ha sido estudiado en profundidad, solo en su taxonomía se ha avanzado en grupos de la amazonía, bioma del cerrado y la Mata Atlántica de Brasil (Silva \& Lima 2007; van der Werff 2008). Tachigali es uno de los pocos géneros que realizan interacciones bióticas complejas como la simbiosis con hormigas (mirmecofilia) (Chomicki et al. 2015), el proceso de modulación y fijación de nitrógeno con Rizobacterias (Moulin et al. 2001). Otra estrategia que ocurre en pocos árboles como Tachigali es la monocarpía donde los individuos adultos de una población después de su única fructificación entran en proceso de muerte (Foster 1977). Este proceso está documentado únicamente en $T$. versicolor y $T$. vasquezii, y es considerado como una estrategia exitosa de supervivencia (Forget et al. 1999; Poorter et al. 2005).

En cuanto al uso y manejo de especies aún no está bien documentada pero se conocen algunas referencias de experiencias como el aprovechamiento de especies maderables de rápido crecimiento, en agroforesteria para la mejora de los suelos por la fijación de nitrógeno. En la Amazonía en general se considera utilidad para la construcción, tintórea y combustible (Ducke 1935), y por- -ser mayormente especie pionera tanto en bosques primarios e impactados goza de un alto potencial para el aprovechamiento en restauración ecológica.

La taxonomía de Tachigali tiene una historia compleja. Comenzó con la descripción de Aublet (1775) de Tachigali paniculata, especie tipo del género. Vogel (1837) describió el género Sclerolobium basado en la especie $S$. denudatum. Durante el siglo XIX y XX los dos géneros se consideraron distintos. Dos grandes tratamientos fueron publicados por Dwyer (1954, 1957a), en la primera consideró 22 especies de Tachigali y en la segunda 34 especies de Sclerolobium. Zarucchi \& Herendeen (1993), Pipoly (1995) y Barneby (1996) comenzaron a transferir especies de Sclerolobium a Tachigali porque ambos comparten una serie de caracteres taxonómicos, tales como el tipo de estambre similar, hipanto subequilatero, equilátero o fuertemente equilátero y frutos en legumbre tipo criptosamara. Recientemente, para las especies de Brasil, Silva \& Lima (2007) transfirieron todas las especies de Sclerolobium y Tachigali. En tanto Van der Werff (2008), en la sinopsis de Tachigali para el bosque amazónico, reconoció 54 especies incluyendo la sinonimización de la totalidad de especies de Sclerolobium.

En el Perú actualmente se reconocen 18 especies (van der Werff 2008), pero estudios detallados vienen revelando la presencia de más de 30 especies (Huamantupa en prensa), las cuales en gran parte son de la región amazónica. Para la región del Cusco se menciona la presencia de solamente tres especies (van der Werff 2008). En el presente estudio se alcanza datos de la sinopsis taxonómica, etnobotánica, ecológica y propuestas de categorías de conservación según la distribución y el impacto antrópico, en la región del Cusco. 


\section{Material y Métodos}

\section{Área de Estudio}

La región del Cusco abarca 71.986,50 km² de territorio (INEI 2014), de ellas aproximadamente el 52\% corresponde al bosque amazónicos (Aragon \& Chuspe 2013), en los que se incluye a los bosques montanos, bosque amazónico de pié de monte y el bosque tropical estacionalmente seco (Josse et al. 2009; Huamantupa 2011). Geopolíticamente los ámbitos que integran al bosque amazónico corresponden a las provincias de Calca, La Convención, Paucartambo, Quispicanchis y Urubamba (Figura 1). Los límites con el departamento de Cusco que incluyen bosque amazónico, se dan por el norte con Junín y Ucayali, por el este con Madre de Dios y Puno, por el oeste con Apurímac y Ayacucho.

\section{Metodología}

Los datos taxonómicos y ecológicos fueron recogidas y generadas de colecciones realizadas en el ámbito de la región del Cusco, los cuales provienen de trabajos de muestreo en campo, monitoreo en parcelas permanentes y colecciones en general. También se incluyó la revisión detallada de muestras depositadas en los herbarios peruanos: CUZ, USM, MOL y HUT. Se complementaron con la consulta en línea de los herbarios MO (http://tropicos.org/), Atrium (http://atrium.andesamazon.org/) y el NY (http://sweetgum.nybg.org/science/vh/), lo $\mathrm{s}$ cuales albergan una gran cantidad de colecciones de plantas peruanas. La revisión taxonómica, discusión y la terminología morfo-anatómica fue en base a obras publicadas y referentes al género Tachigali (e.g. Ducke 1922, 1935; Dwyer 1954, 1957; Font Quer 1982; Zarucchi \& Herendeen 1993;
-Pipoly 1995; Barneby 1996; Lewis 2005; Silva \& Lima 2007; van der Werff 2008). La diagnosis taxonómica está estrictamente aplicada para el material analizado en el ámbito de la región del Cusco. Se compara con otras descripciones bibliográficas, también para cada especie se cita la publicación original del tipo descrito y publicado, y a su vez se enfatizó en las últimas actualizaciones en cuanto a las identificaciones. Para la obtención de datos etnobotánicos se basó en encuestas simples a pobladores locales, referidos principalmente al uso y nomenclatura vernacular.

Para la inclusión en alguna categoría de amenaza a las especies de Tachigali en la región de Cusco, se evaluó siguiendo los criterios de la (IUCN) Unión Internacional para la Conservación de la Naturaleza (2001), versión 3.1, actualizada al 2014. Las categorías se aplicaron bajo los criterios siguientes: a) de acuerdo al nivel actual de explotación de sus poblaciones expresada en porcentaje b) rango geográfico en relación a la disminución de su población en su hábitat, c) tamaño de población o número de individuos maduros o semilleros, d) estimaciones del estado de conservación relacionados al tamaño de su población y e) análisis a priori que estime qué porcentaje de la población se extinguirá en un número determinado de generaciones o años. Se identifican nueve categorías: Extinta (EX), Extinta en estado silvestre (EW), En peligro crítico (CR), En peligro (EN), Vulnerable (VU), Casi amenazada (NT), Preocupación menor (LC), Datos insuficientes (DD) y No evaluado (NE), especie no evaluada para ninguna de las otras categorías. Estos criterios no fueron aplicados estrictamente, dado que nuestra propuesta es a nivel regional de menor área, sin embargo se adoptó para contribuir a la categorización de las especies a nivel local. 


\section{Resultados y Discusión}

Se reconocen nueve especies del género Tachigali para la región cusqueña, de ellas tres corresponden a morfoespecies, que aparentemente corresponden a potenciales especies nuevas. La totalidad de estas se encuentra distribuida en el bosque amazónico, pero $T$. setifera y $T$. vasquezii alcanzan a habitar bosques pre-montanos, y solo Tachigali sp. 2 habita exclusivamente en el bosque premontano.

Los datos etnobotánicos indican que el $100 \%$ de las especies son usados como combustible, el $80 \%$ son aprovechados en la actividad del comercio maderero, el 70\% son utilizadas en programas de reforestación y agroforestería principalmente en cultivos mixtos de café, cacao y otros. Solo T. guianensis es ocasionalmente utilizado como tinctoreo natural. Estos datos corroboran en gran medida al uso que se le da a las especies de Tachigali en varios lugares de los bosques amazónicos del neotropico.

De acuerdo a su estado poblacional, conservación, uso y manejo, aplicando los criterios de la IUCN (2001), se propone incluir a las especies $T$. guianensis, T. macbridei, $T$. paniculata y $T$. setifera, en la categoría de preocupación menor (LC), T. chrysaloides, T. vasquezii y Tachigali sp. 3 como casi amenazada (NT) y Tachigali sp. 1 y Tachigali sp. 2 como vulnerables (VU), por las pocas poblaciones presentes en la región del Cusco.

La presencia de las nueve especies de Tachigali en la región del Cusco hace poner en evidencia la alta diversidad de árboles para el Cusco, lo cual se ha documentado previamente con el alto endemismo de otros grupos (León et al. 2006). En términos comparativos de las 18 especies reconocidos para el Perú en el- -tratamiento de van derWerff (2008), en el presente estudio se reconoce el $50 \%$ de especies, lo cual también refleja la falta de estudios taxonómicos en profundidad.

A nivel regional la diversidad de Tachigali en el Cusco es comparable a regiones de mayores extensión territorial como de Loreto en el norte peruano, al dominio brasilero de la Mata Atlántica donde solo se reconoce la presencia de 10 especies (Silva \& Lima 2007; Silva et al. 2016).

A pesar que el presente estudio integra varios registros de Tachigali, colectados y evaluados en varios lugares de la Amazonía cusqueña, aún la mayor parte no fue explorada y estudiada, como las zonas del Bajo Urubamba, las áreas protegidas del Santuario Nacional del Megantoni, reserva comunal Matshiguenka, ambas inmersas en las provincias de La Convención y Paucartambo, las áreas limítrofes entre el bajo Urubamba y el parque nacional del Manu en Madre de Dios y los valles del Río Apurímac en las localidades de Pichari y Quimbiri. Esto sugiere que la diversidad de este género de árboles aún es incierta y con seguridad irán incrementándose con mayores estudios. 


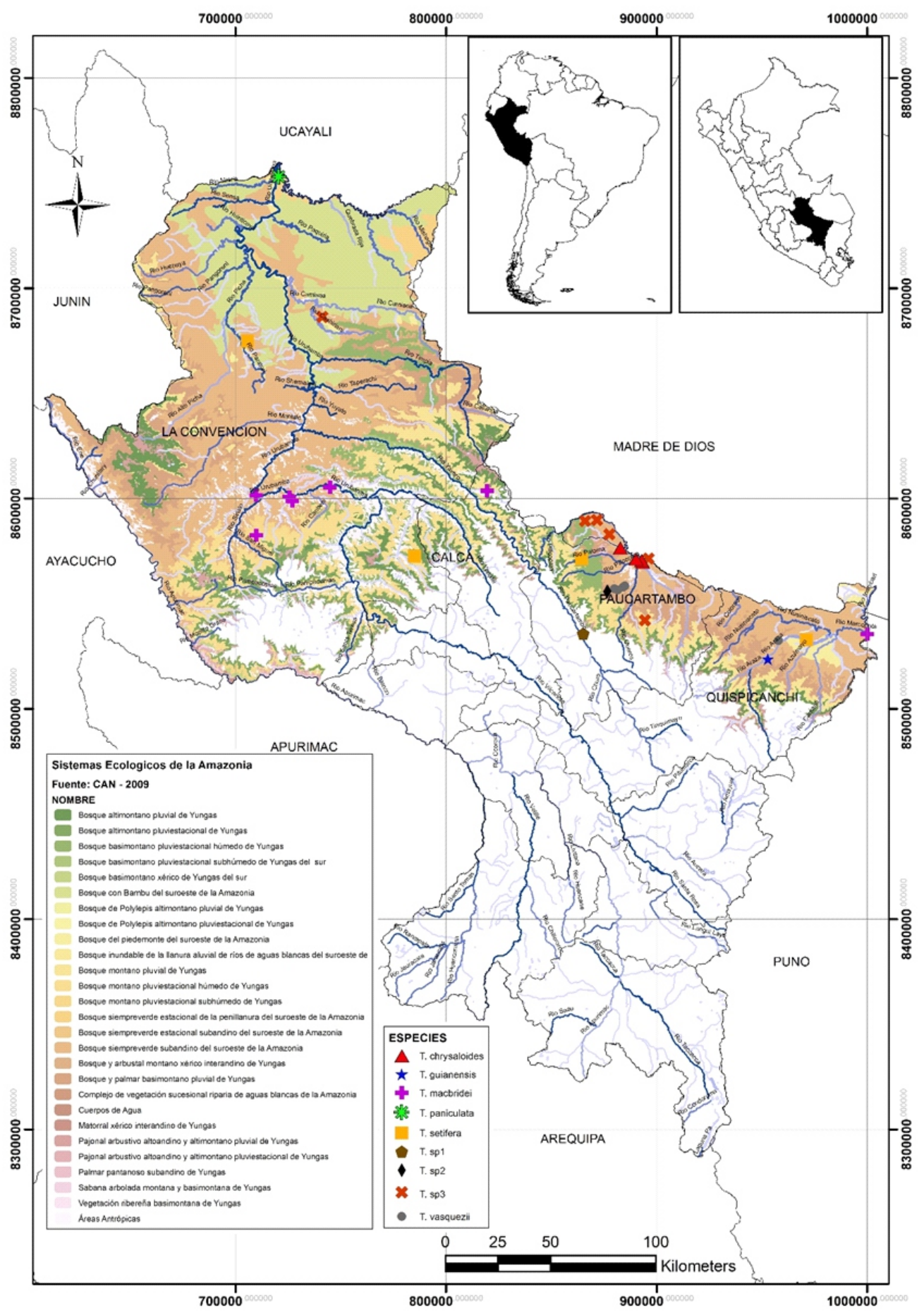

Figura 1. Mapa de distribución del género Tachigali en la región del Cusco. 


\section{Clave de identificación del género Tachigali en la región del Cusco}

1. Ramas y raquis de peciolo angulado, trígono; flores $\geq 1 \mathrm{~cm}$

T.paniculata

$\mathbf{1}^{\prime}$. Ramas y raquis peciolar en terete, semiterete no angulado; flores $<1 \mathrm{~cm}$

2. Peciolo con domacio desarrollado; base de foliolo fuertemente inequilatero.....

T.macbridei

2 '. Peciolo sin domacio o con esta poco evidente; base de foliolo poco inequilatero.

3. Ausencia de estipulas; 6-7 pares de folíolos, base de folíolos obtuso.

Tachigali sp. 1

3'. Presencia de estipulas; 7-12 pares de folíolos, base de folíolos no obtuso

4. Estipula pectinada fuertemente hirsuta; flores bracteadas

T.guianensis

4'. Estipula foliosa, no pectinada; flores no bracteadas.

5. Estipulas foliosas pediceladas; frutos maduros con exocarpo oscuro......

Tachigali sp. 3

5'. Estipulas foliosas no pediceladas; frutos maduros con exocarpo no oscuro

6. Foliolos elípticos, base decurrente; flores sésiles Tachigali sp. 2

6'. Foliolos oblongos, base cordada a semicordada; flores pediceladas .....

7. Ramitas y raquis terete y pilosidad compacta; pétalos lineares, fuertemente pilosa...T. setifera

7'. Ramitas semitere, semi-angulada, con pilosidad laxa; pétalos lineares, poco pilosa..... .8

8.Tallos y ramas semiterete; hipanto sub-equilatero; frutos 12-17 cm de largo...T.chrysaloides 8'.Tallos y ramas tetramera; hipanto inequilatero; frutos 3-8.4 cm de largo. T. vasquezii

1.Tachigali chrysaloides van der Werff, Ann. Missouri Bot. Gard. 95: 636. 2008. Tipo: Ecuador. Morona-Santiago: Cordillera de Cutucu, along Patuca-Santiago rd., 600-1000 m, 23 Oct. 1988, L. Dorr \& L. Barnett 5824 (holotipo: NY!; isotipos: MEL!, MO!).

Diagnosis. Árbol $35 \mathrm{~m}$, tronco rojizoanaranjado, irregular; ramas semiterete, apicales pubescente-tomentulosos de color marrón-rojizo. Estipulas 2-5 $\times 1-2.8 \mathrm{~cm}$, foliáceas, enteras, fuertemente revolutas, rugosa-bullada, venación pronunciada y marcada. Hojas hasta $1.2 \mathrm{~m}$ de longitud, raquis semiterete, canaliculado; domacio rudimentario desde la base del raquis hasta la mitad, abundantes hormigas; 8-9 pares de foliolos, base de los foliolos levemente asimétricos, envés densamente pubescente, - -marrón-blanquecino y dorado en foliolos jóvenes. Inflorescencias en panículas densas hasta $50 \mathrm{~cm}$ de largo. Flores 7-8 mm, hipanto subequilatero, hasta $2 \mathrm{~mm}$ de largo, blanco cremoso; pétalos hasta $3 \mathrm{~mm}$ de largo, lineares; estambres hasta $5 \mathrm{~mm}$ de largo. Frutos en criptosamaras elipticas, 2-3.5 $\times 12-17 \mathrm{~cm}$, epicarpo negruzco de maduros, con 1 a 2 semillas (Figura 2).

Discusión. Esta especie es muy próxima de T. prancei y T. setifera (van der Werff 2008), la diferencia marcada de estas es por la desarrollada y marcada estipula en $T$. chrysaloides. Pero en nuestras revisiones hemos hallado que esta especie también está próxima de $T$. vasquezii, con la cual concuerda las descripciones de todas las características, incluidas el tipo de indumento- 
(cf. van der Werff 2008), pero aún especímenes en flores no se colectaron de $T$. vasquezii. Otro argumento que apoya a que aparentemente $T$. chrysaloides está dentro de $T$. vasquezii, es que ambos se encuentran compartiendo el mismo hábitat en la región del Cusco y sur peruano. Estudios más profundos seguramente revelaran de las entidades verdaderas de estas dos especies.

Ecología. Tachigali chrysaloides habita bosques asociados a suelos pobres arcillosos y arenosos, desde los 350-1020 msnm, en Cusco son abundantes las poblaciones en las localidades del valle de kosñipata, en el valle de Quincemil y algunas zonas del bajo Urubamba en la provincia de la Convención. Los periodos de fructificación se dan de marzo a junio.

Conservación y Usos. Es conocida localmente como "inka pacay", "chira pacay" y "paca pacay". En varios lugares es frecuentemente utilizado en agroforesteria en cultivos de café y otros frutales, es frecuente observar plantaciones destinadas al aprovechamiento forestal para el comercio de su madera que goza de un rápido crecimiento y de buena calidad. Se sugiere categorizar como casi amenazada (NT).

Material analizado. Cusco: Prov. Paucartambo. Dist. Kosñipata. Sector Pelayoc, Coloradito. 18 Agosto 2016, 643 m, 19L 2424078578105 , I. Huamantupa \& M. Luza 19437 (CUZ).

2. Tachigali guianensis (Benth.) Zarucchi \& Herend., Monogr. Syst. Bot. Missouri Bot. Gard. 45: 1254. 1993. Basionimo: Sclerolobium guianense Benth., Hooker's J. Bot. Kew Gard. Misc. 2: 237. 1850. Tipo: Guyana. Rob. Schomburgk 2nd coll. 598 (lectotipo: K no visto, designado por Zarucchi \& Herendeen en Brako \& Zarucchi, 1993: 1254; isolectotipos: BM!, P!).
Sinónimos. Sclerolobium radlkoferi Rusby, Sclerolobium uleanum Harms, Sclerolobium tinctorium var. uleanum (Harms) Dwyer, Tachigali uleana (Harms) Zarucchi \& Herend., Sclerolobium subbullatum Ducke, Tachigali subbullata (Ducke) L. F. Gomes da Silva \& H. C. Lima.

Diagnosis. Árboles hasta $30 \mathrm{~m}$; tronco blanco a oscuros, irregular; ramas densamente pubescentes con indumento en forma de $\mathrm{T}$ pronunciado y rojizo. Estipulas $2-5 \mathrm{~cm}$ de largo, pectinadas rojizas, densamente tomentosas. Hojas 50-75 cm de largo; sin domacios; foliolos 7-11 pares, 6-14 cm de largo, has y envés pubescentes, con mayor notoriedad en las venas, base cordada y asimétrica. Inflorescencias inmaduras con brácteas elongadas y densamente pilosas. Flores 6-7 mm, bracteadas, blanco-cremosa; hipanto 1.5-2 mm de largo; pétalos $0.2 \times 1.3$ $1.6 \mathrm{~mm}$, lineares, glabros. Frutos $2-3 \times 6-8 \mathrm{~cm}$ (Figura 3).

Discusión. Tachigali guianensis comprendió a varias entidades ya mencionadas actualmente como sinónimos, los que fueron diferenciadas básicamente por las variaciones extremas de los indumentos (densamente hasta laxamente), a pesar que verticilos florales comprenden el mismo patrón. Sin embargo dependiendo de la región esta especie tiene variaciones locales.

Ecología. En los bosques amazónicos cusqueños está ampliamente distribuida desde los 300 hasta los 900 msnm, comprendiendo inclusive localidades con bosques secos estacionales en las localidades de Quillabamba y Yavero. Es frecuente encontrar en áreas de suelos poco fértiles y arcillosos, además de claros con impacto antrópico. Se observaron en floración entre diciembre y marzo, frutos de marzo a junio. 


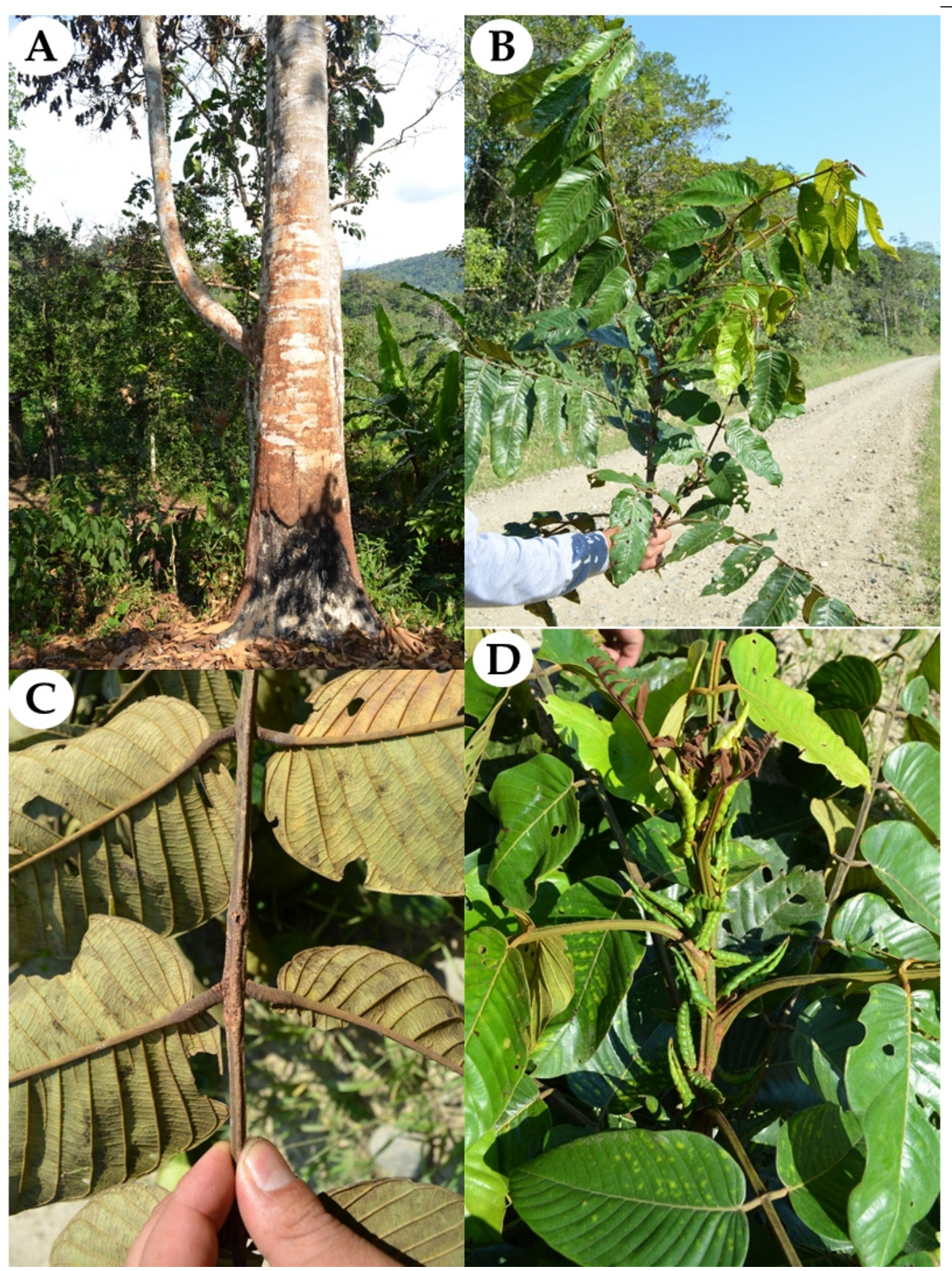

Figura 2. Tachigali chrysaloides. A. Tallo, B. Rama, C. Raquis de hoja con el domacio rudimentario \& D. Rama apical mostrando las estipulas. 


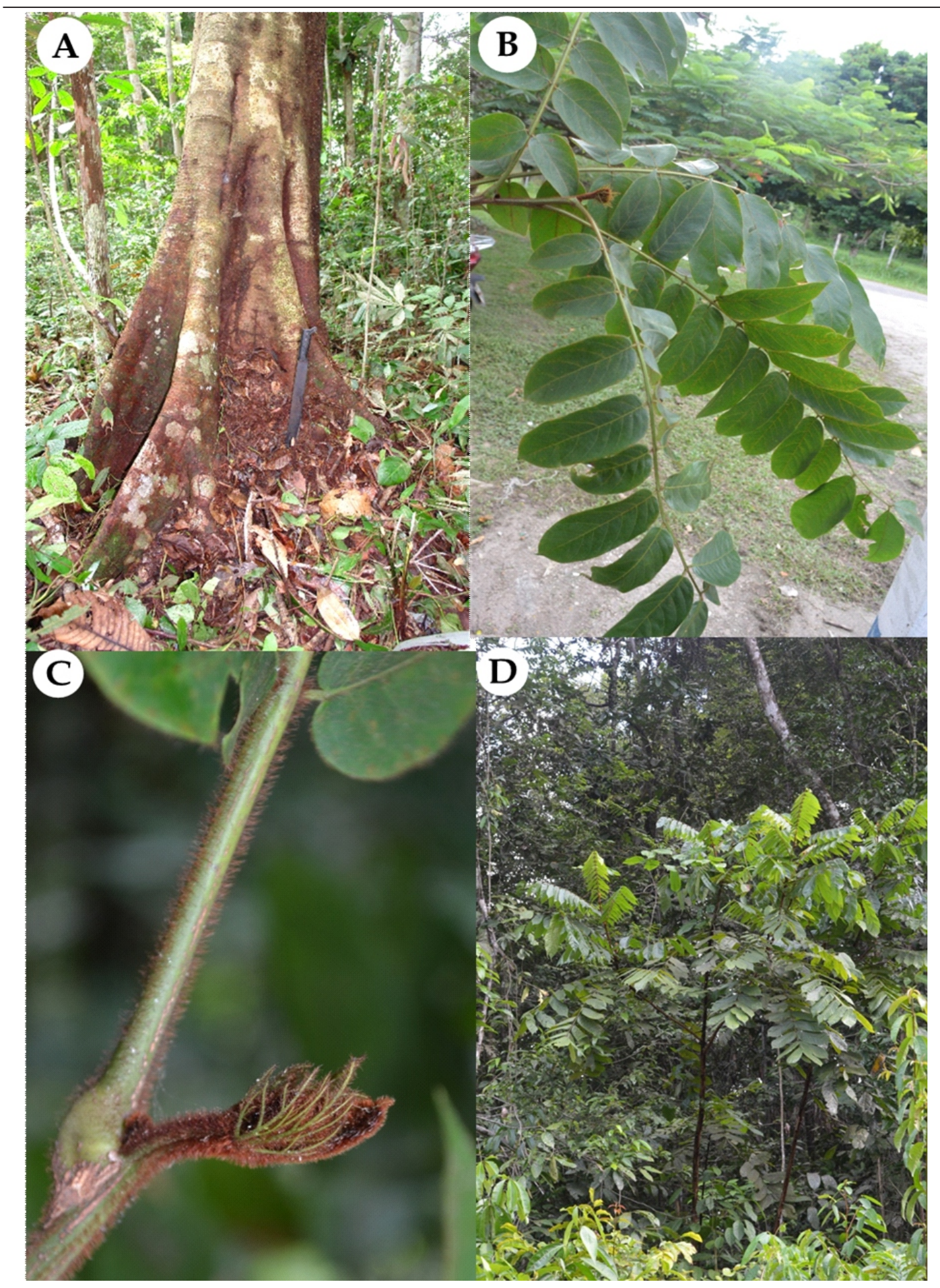

Figura 3. Tachigali guianensis. A. tronco, B. Ramas y hojas, C. Estipulas \& D. Hábito. 
Conservación y Usos. Localmente se la conoce como "inka pacay", "palo mierda" y "asna pacay". En pocos lugares es utilizado en agroforesteria, (Quillabamba, Lacco Yavero), ocasionalmente su madera es aprovechada para el comercio. Frecuentemente es aprovechada como combustible, mencionando que esta especie así tenga la madera "mojada o verde" genera buena combustión. En algunos mercados de Cusco se pudo registrar las hojas como tinctorea, aparentemente fue utilizada por antiguos peruanos para estos fines. No está incluida en ninguna categoría de amenazaprotección en la región y el Perú. Consideramos categorizar como con preocupación menor (LC), ya que también esta especie está ampliamente distribuida en el neotropico.

Material analizado. Cusco: Prov. Quispicanchis. Distr. Camanti, Maniti, 26 Noviembre 1990, $720 \mathrm{~m}, 13^{\circ} 17^{\prime} 00^{\prime \prime S}$ 7048'00"W, Timana 1159 (MO). Prov. La Convención, Dist. Echarati, Cirialo, 950 m, I. Huamantupa et al. 7979 (CUZ); Cirialo, 980 m, I. Huamantupa et al. 10129 (CUZ); Cirialo, 950 m, I. Huamantupa et al. 8016 (CUZ); Echarati, 850 m, I. Huamantupa et al. 7449 (CUZ); Chuankiri, 1000 m, I. Huamantupa et al. 8022 (CUZ).

3. Tachigali macbridei Zarucchi \& Herend., Monogr. Syst. Bot. Missouri Bot. Gard. 45: 1254. 1993. Reemplazado de: Sclerolobium rigidum J. F. Macbr., Field Mus. Nat. Hist. Bot. Ser. 13: 201. 1943, non Tachigali rigida Ducke, 1938. Tipo: Peru. Loreto: Pumayacu, Klug 3239 (holótipo: F; isotipos: $\mathrm{GH}$ !, MO!).

Sinónimos. Sclerolobium rigidum J. F. Macbr., Tachigali rigida Ducke.
Diagnosis. Árbol hasta $30 \mathrm{~m}$; tronco blancusco, irregular, bifurcados frecuentemente a 5-8 m; ramas con pubescencia seríceo anaranjado, principalmente de jóvenes. Estipulas pectinadas a veces bastante desarrolladas, caducas en ramas adultas. Hojas con raquis en terete, levemente sulcado; domacio en terete, generalmente sulcado; foliolos 7-10 pares, envés pubescente, blanco seríceo, base fuertemente cordada e inequilatera; Inflorescencia con indumento furruginosa rojiza. Flores 7-8 mm, sésiles; pétalos 1-1.6× 2-3 mm, filiformes glabros. Frutos 2-3.6 $\times$ 6.2-8.5 cm, elípticos, exocarpo glabro, con $1 \mathrm{a}$ 2 semillas, generalmente una (Figura 4).

Discusión. Tachigali macbridei es de fácil reconocimiento por la combinación de presencia de domacios desarrollados, tricomas erectos y la estípula fuertemente pectinada y habita en lugares expuestos a claros. Esta especie es similar a T. guianensis pero esta última no presenta domacios y tiene tricomas rojizos, no erectos.

Ecología. Se la puede encontrar en áreas de claros asociados a suelos intervenidos y claros naturales. En los bosques amazónicos cusqueños esta especie está ampliamente distribuida desde los 300 hasta los 900 msnm, comprendiendo inclusive localidades con bosques secos estacionales en las localidades de Quillabamba y Yavero. Es frecuente encontrar en áreas de suelos poco fértiles y arcillosos, además de claros con impacto antrópico. La floración se da de junio a setiembre y frutos de agosto a diciembre.

Conservación y Usos. Localmente se la conoce como "yurac pacay", "inka pacay" y “palosanto”. En algunas localidades es utilizada para comercio de la madera, como- 


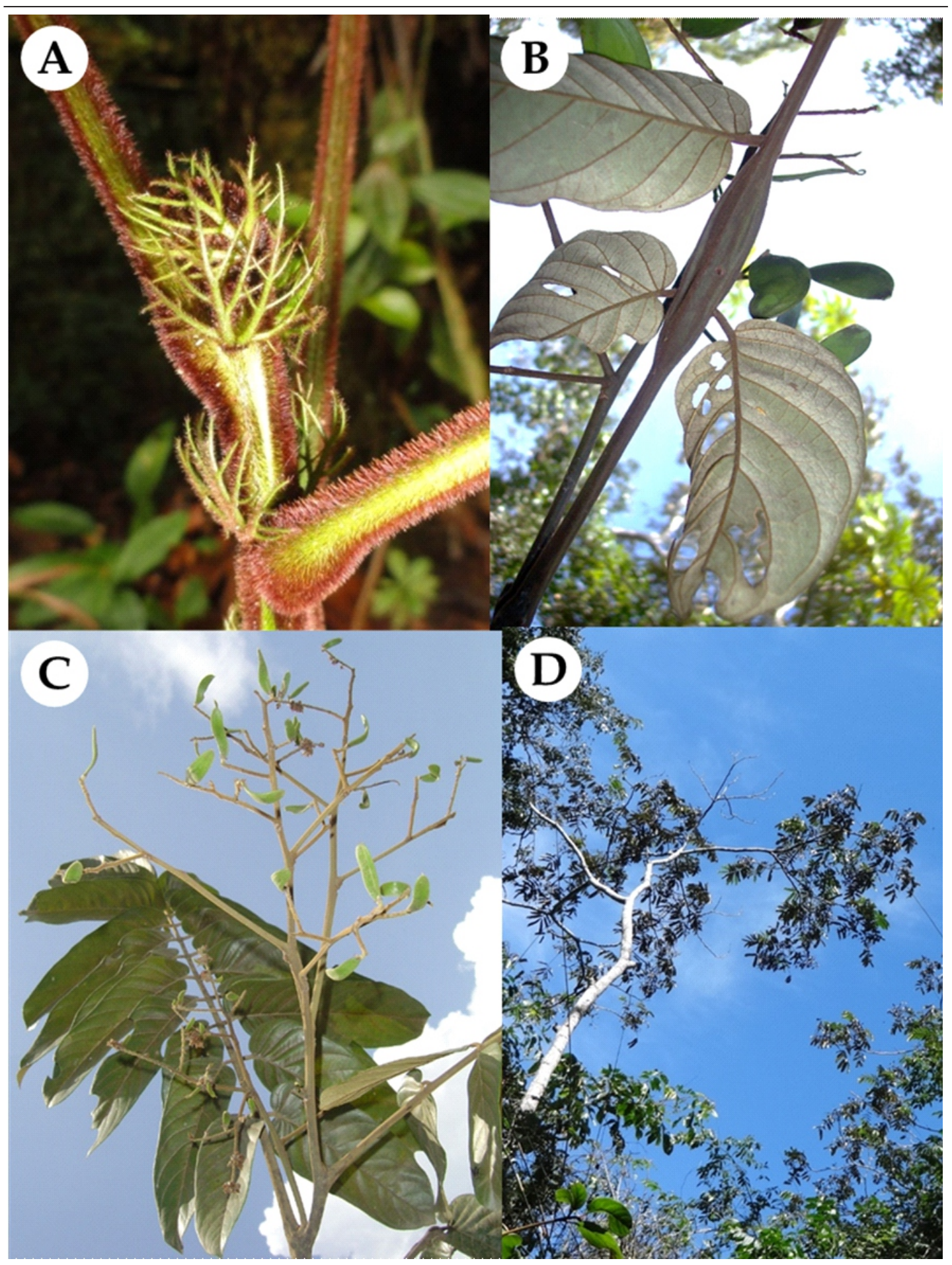

Figura 4. Tachigali macbridei. A. Estipulas, B. Domacio, C. Rama en frutos inmaduros \& E. Habito con ramas en flores. 
-combustible y como cercos naturales por la presencia de las hormigas. No está incluida en ninguna categoría de amenaza-protección en la región y el Perú. Consideramos categorizar como, con preocupación menor (LC).

Material analizado. Cusco, Prov. La Convención: 17 Noviembre 2005, $800 \mathrm{~m}$,

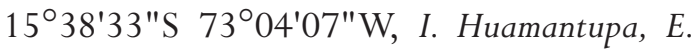
Suclli \& A. Carazas 7225 (AMAZ, CUZ, HUT, MO, USM); 25 Marzo 2006, $1320 \mathrm{~m}$, $12^{\circ} 39^{\prime} 59^{\prime \prime S} 72^{\circ} 54^{\prime} 39^{\prime \prime W}$, I. Huamantupa, L. Valenzuela \& J. Farfán 7395 (CUZ, MO); 26 Marzo 2006, $1320 \mathrm{~m}, 12^{\circ} 39^{\prime} 59^{\prime \prime S}$ 7254'39"W, I. Huamantupa, L. Valenzuela \&J. Farfán 7436 (CUZ, MO); 26 Marzo 2006, 1036 m, 12 $38^{\prime} 56^{\prime \prime S ~ 72} 55^{\prime} 25^{\prime \prime W}$, L.Valenzuela 6754 (AMAZ, CUZ, HUT, MO, MOL, USM); 24 Agosto $2006,600 \mathrm{~m}, 12^{\circ} 36^{\prime} 52^{\prime \prime S}$ 07303'37"W, L. Valenzuela 7661 (AMAZ, CUZ, HUT, MO, MOL, USM); 16 Agosto

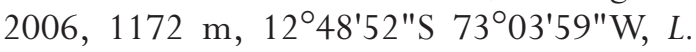
Valenzuela 7860 (CUZ, HUT, MO, USM).

4. Tachigali paniculata Aubl., Hist. Pl. Guiane 1: 372. 1775. Tipo: Guayana Francesa. Aublet s.n. (holotipo: BM!; isotipo: G!).

Sinónimos. Tachigali trigona Aubl., Tachigali eriocalyx Tul., Tachigali paniculata var. angustifolia (Miq.) Dwyer, Tachigali grandiflora Huber, Tachigali ulei Harms, Tachigali rusbyi Harms, Tachigali pulchra Dwyer, Tachigali paniculata var. comosa Dwyer.

Diagnosis. Árbol frecuentemente de dosel medio hasta $20 \mathrm{~m}$; ramas anguladas, tetra-anguladas, trigonas, a veces cristadas, a veces huecas, glabras a hirsuto villosas. Estipulas foliosas lobuladas, pectinatiformes. Hojas con raquis angulado (trígono); domacio presente a veces ausente, poco notorio, con- -orificios, siempre está asociada a la presencia de hormigas; foliolos con 4-9 pares, peciolulos cortos a sésiles, articulados al raquis, foliolos oblongo, elípticos hasta falcados, glabros en el has, villoso-hirsuto en el envés. Inflorescencia en panículas. Flores relativamente grandes, $1-1.5 \mathrm{~cm}$ de largo, amarillo cremosas; cáliz 5-7 mm de largo, inequilatera; pétalos 5-7 mm de largo, desarrollados amarillo-anaranjados, oblongo espatulados; estambres heteromorfos hasta de 0.7-1 cm de largo. Frutos 1.5-2.4 × 3.2-6.4 $\mathrm{cm}$, elípticos, raramente oblongos, con una a dos semillas (Figura 5).

Discusión. Tachigali paniculata comprende diversas variaciones que previamente fueron sinonimizados por van der Werff (2008), la mayoría de ellas correspondían a especies que en algunos casos solo mostraban variaciones regulares a pequeñas como la presencia de mayor número de foliolos, mayor tamaño de estambres, cáliz y pétalos. Pero el patrón marcado de T. paniculata s.l. es la presencia de ramas y raquis anguladas, con peciolulos articulados, flores grandes $(\geq 1 \mathrm{~cm})$ en comparación a otras especies; estambres heteromorfos; cáliz piloso seríceo. Las especies más próximas por su similitud es T. glauca, que se diferencia por presentar raquis semiterete, domacio y estipula foliosa oblonga, y T. catingae, por presentar raquis semiterete y ausencia de indumento piloso-seríceo.

Ecología. En la región amazónica de Cusco, es conocida solo de algunos individuos registrados en el Bajo Urubamba (Camisea), donde se localizó en bordes de áreas inundables y lagunas, aparentemente los bosques amazónicos de la región cusqueña son los límites de su distribución en el extremo sur, desde los 200 a los $400 \mathrm{msnm}$. Son conocidas mayores poblaciones en el norte del País. Los- 


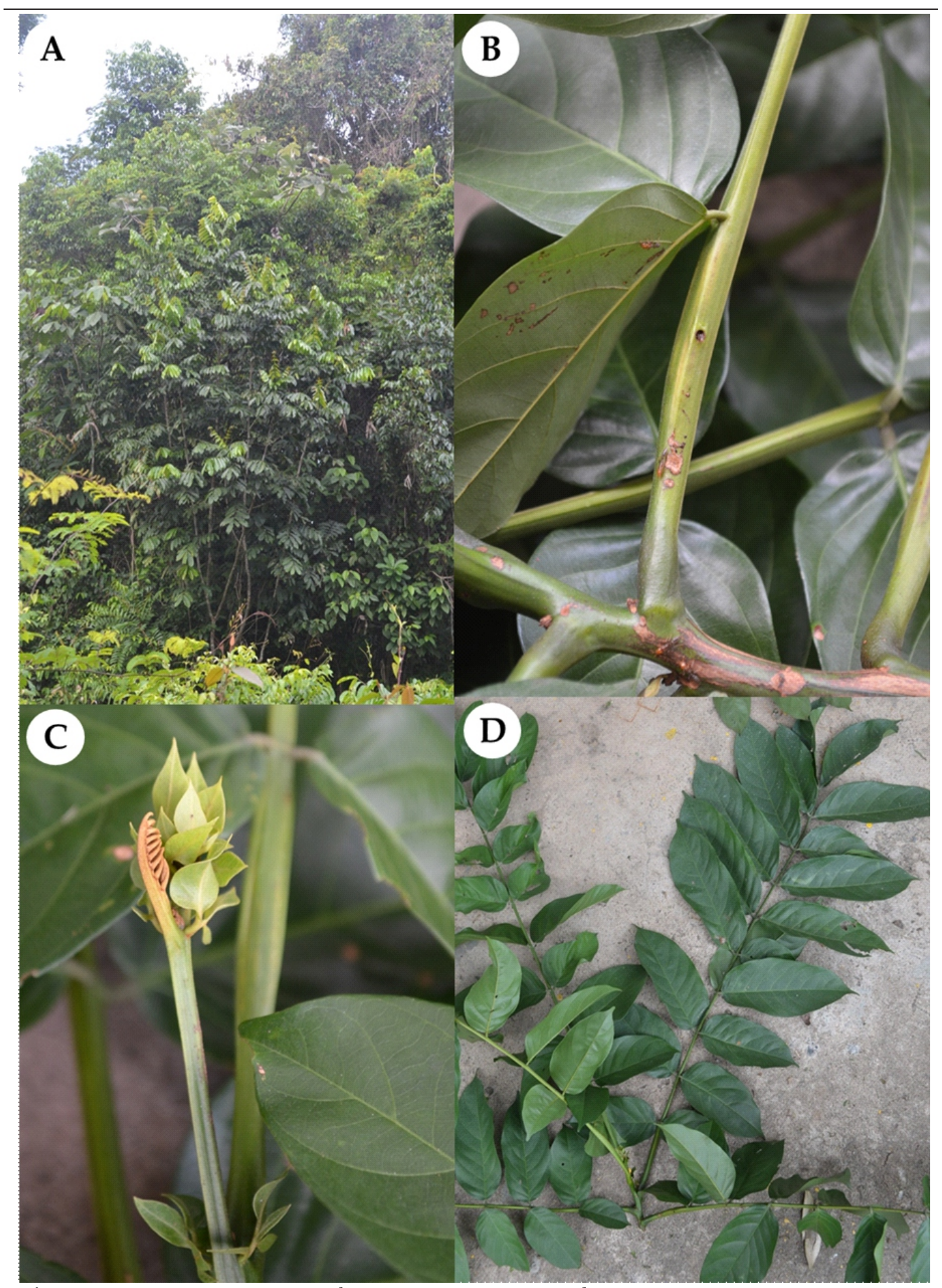

Figura 5. Tachigali paniculata. A. Habito, B. Domacio, C. Estipulas \& D. Rama vegetativa. 


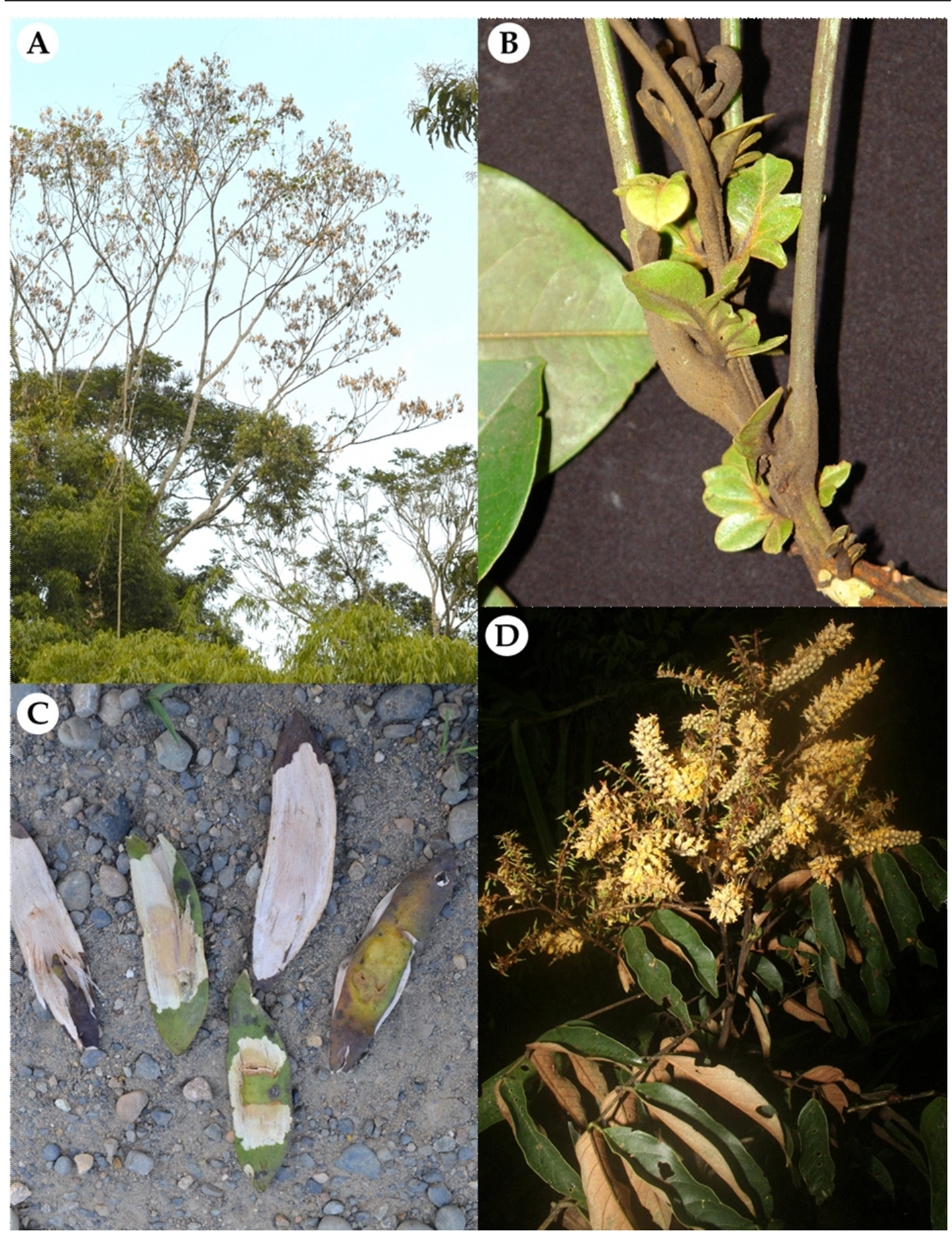

Figura 6. Tachigali setifera. A. Habito, individuo en fructificación, B. Estipulas, C. Frutos \& D. Rama en floración (Foto M. Chambi-ATRIUM). 
-periodos de floración se dan de diciembre a abril y de fructificación de junio a diciembre.

Conservación y Usos. Localmente se la conoce como "shiru”, "tangarana” y "palosanto". No se conoce de algún uso en las comunidades locales. No está incluida en ninguna categoría de amenaza-protección en la región y el Perú. En el presente estudio se propone considerar como en preocupación menor (LC), ya que tiene poblaciones saludables en el límite nor- oeste de la región amazónica del Cusco.

Material analizado. Cusco. Prov. La Convención. Dist. Echarati, Bajo Urubamba, 18 Julio 2012, 325 m, 18L 720537.98 8753145.85, M.Luzas.n. (CUZ).

5. Tachigali setifera (Ducke) Zarucchi \& Herend., Monogr. Syst. Bot. Missouri Bot. Gard. 45: 1254. 1993. Basionimo: Sclerolobium setiferum Ducke, Arq. Inst. Biol. Veg. 2: 42. 1935. Tipo: Brasil. Amazonas: "silva non inundabilis coliniae Campos Salles prope Manaos", Ducke s.n. (lectotipo: RB 23329, designado por Zarucchi \& Herendeen in Brako \& Zarucchi, 1993: 1254; isolectotipos: P!, US!, $\mathrm{G} !)$.

Diagnosis. Árboles medianos, hasta $35 \mathrm{~m}$; ramas piloso setigeros y con pelos compactos, rojizos-canescentes. Estipulas foliosas, tri o bilobadas, a veces revolutas de adultas. Hojas hasta $1 \mathrm{~m}$ de largo; domacio ausente; foliolos 8 12 pares, oblongos, elípticos, lanceolados; has generalmente glabro, envés con indumento variable desde cortos compactos hasta levemente hirsutos, presencia de pelos capitados de porte mayor. Inflorescencia en panículas compactas. Flores pequeñas, 5-6 $\mathrm{mm}$, pedicelos sésiles a semisésil; cáliz cerca 4 $\mathrm{mm}$ de largo; pétalos 1-1.2 × 2-3 mm- -lineares-oblongos, en la base fuertemente hirsuto villoso de color amarillo vivo; estambres heteromorfos, hirsutos lanados. Fruto 2.4-2.8 $\times 4.2-6.3 \mathrm{~cm}$, elípticos, falcado, glabro, levemente hirsuto, con 1-2 semillas (Figura 6).

Discusión. Tachigali setifera s.l. actualmente comprende algunas variaciones morfológicas. Las especies más próximas de esta son: Tachigali rugosa, T. prancei, T. vasquezii, $T$. micropetala y $T$. chrysaloides, pero de ellas $T$. setifera es la única que presenta el indumento tapizado-compacto y la presencia de pelos capitados sobresalientes. Aparentemente esta comprende a otras entidades taxonómicas que con mayores estudios seguramente serán revelados.

Ecología. En la región del Cusco se distribuye en el bosque amazónico húmedo y llega hasta el bosque amazónico pre-montano (250-1300 msnm), en esta gradiente esta especie, prefiere suelos ricos, también es frecuente registrarla en claros naturales. Los periodos de floración y fructificación son entre marzo y junio.

Conservación y Usos. Localmente es conocida como "inkapacay", "paca pacay", "kellopacay". Es utilizada como una especie alterna en el comercio maderero, en algunas localidades como en el valle de Quincemil y Kosñipata son usadas en programas de reforestación local. No está incluida en ninguna categoría de amenaza-protección en la región y el Perú. En la presente se sugiere considerar en preocupación menor (LC), ya que se tiene poblaciones saludables en toda la región del Cusco.

Material analizado. Cusco, Prov. Paucartambo, Dist. Kosñipata, Pongo de Qoñec, 01 Enero 2006, 800 m, 1253'53"S $72^{\circ} 22^{\prime} 25^{\prime \prime}$, I. Huamantupa \& I. Huamantupa 7346 (CUZ, MO); 27Agosto 2016, 820 m,- 
-19L 213050 8572353, I. Huamantupa \&D. Huamán 19523 (CUZ); Prov. Quispicanchis, Dist. Camanti-Quincemil, 750 m, 19L 320619 8536466, M. Chambi 93 (USM).

6. Tachigali vasquezii Pipoly, Sida 16: 408. 1995.Tipo: Perú. Amazonas: Valle del Río Santiago, Quebrada Caterpiza, Huashikat 1910 (holótipo: $\mathrm{MO} !)$.

Diagnosis. Árbol hasta $30 \mathrm{~m}$; ramas semiteretes, tetrameras tomentulosas, sericeoblanquecinas. Estipulas desarrolladas, folioso revolutas, rugosas Hojas hasta 1.5 m de largo; raquis semiterete sulcado; domacio presente a lo largo del raquis, con presencia de hormigas; foliolos 8-10 pares, oblongos ovados, base equilátera sub-cordada, decurrente, haz escabroso-piloso, envés tomentuloso, marróngrisáceo, venas secundarias bien marcadas en el envés; foliolos nuevos con envés fuertemente tomentuloso marrón oscuro (achocolatado). Inflorescencia en panículas amplias. Flores hasta el presente no observadas de colección alguna. Frutos 2-3.2 × 3-8.4 cm, elípticos, hipanto inequilatero, con 1 a 2 semillas (Figura 7).

Discusión. Esta especie es considerada enigmática por que no se conoce de colección en flores, inclusive la descripción tipo corresponde a una especie en frutos. Se asemeja bastante a $T$. chrysaloides e inclusive ambas co-habitan los mismos lugares, seguramente estudios posteriores definirán su taxonomía. Otra especie similar es T. prancei, pero esta tiene indumento tomentoso rojizo y de mayor tamaño, hojas ovado elípticas, frutos elípticos de mayor tamaño y habita las regiones de Acre y Rondônia en Brasil, en la zona transicional del bioma Cerrado y Amazonia. Tachigali vasquezii es otra de las pocas especies- -que realiza monocarpia y aparentemente esta proceso aun no es bien conocido dado que observaciones en campo corroboran que los individuos no mueren por completo en una primera fructificación sino en una posterior.

Ecología. Se concentra ampliamente en los valles de Kosñipata y Quincemil, donde está asociado a suelos ricos. Se registraron poblaciones desde los 500 hasta los 1350 msnm. Aparentemente las mayores poblaciones de esta especie están en el sur peruano (Cusco, Madre de Dios y Puno). Los periodos de fructificación se dan de noviembre a marzo.

Conservación y Usos. Localmente es conocida como "inkapacay" y "kellopacay". Es aprovechada en el comercio maderero, se registraron individuos hasta de 120 de dap. Es aprovechada en algunas localidades en programas de reforestación local. No está incluida en ninguna categoría de amenazaprotección en la región y el Perú. Se propone incluir en la categoría de casi amenazada (NT) para la región del Cusco, que al parecer sus poblaciones están confinadas a las faldas de las montañas del bosque pre-montano.

Material analizado. Cusco, Prov. Paucartambo, Dist. Kosñipata, Chontachaca, 18 Agosto 2016, 828 m, 19L 2338788559787, I. Huamantupa \&M.Luza 19461 (CUZ). 


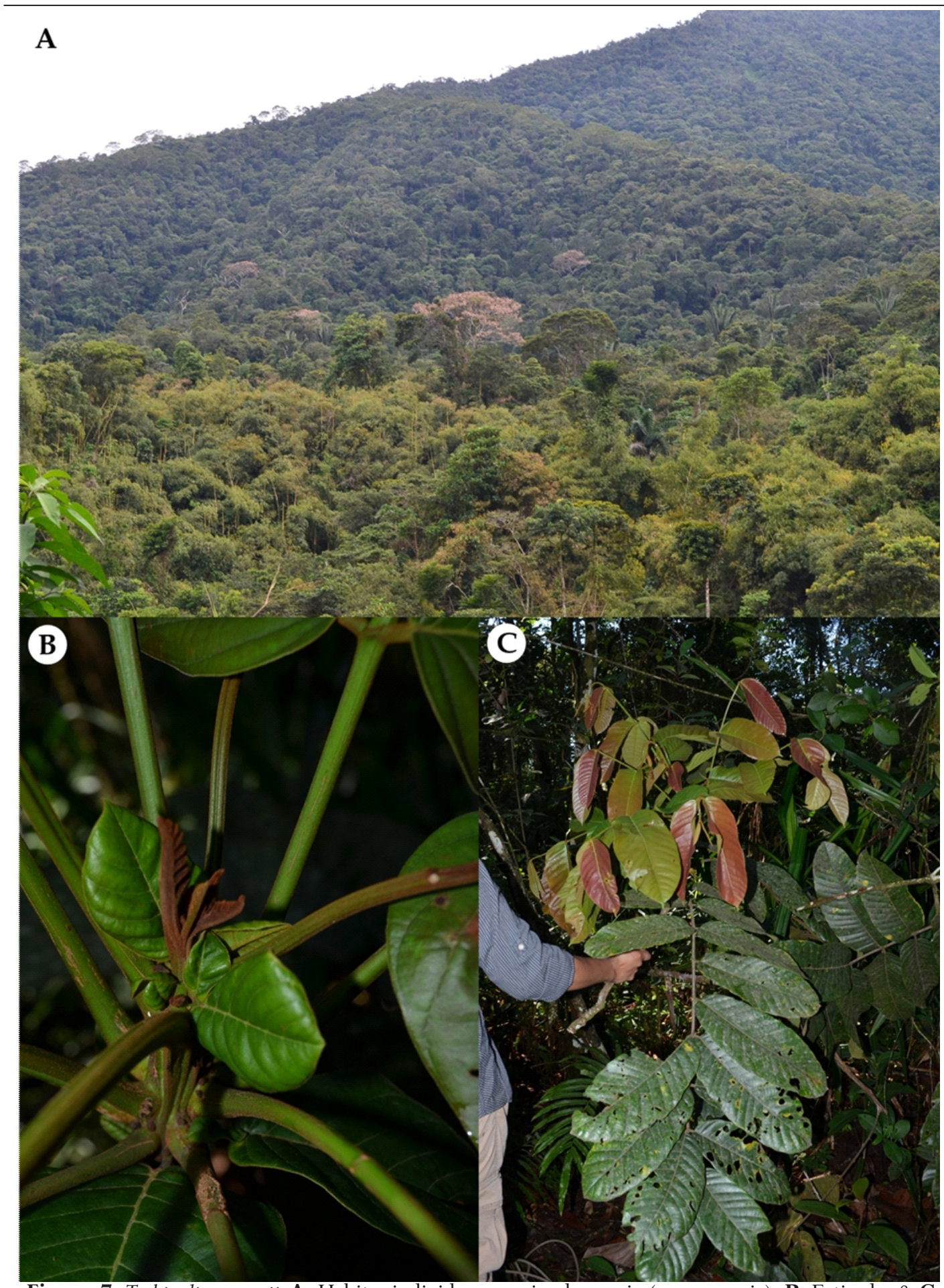

Figura 7. Tachigali vasquezii. A. Habito, individuos muriendo en pie (monocarpia), B. Estipulas \& C.

Rama vegetativa. 


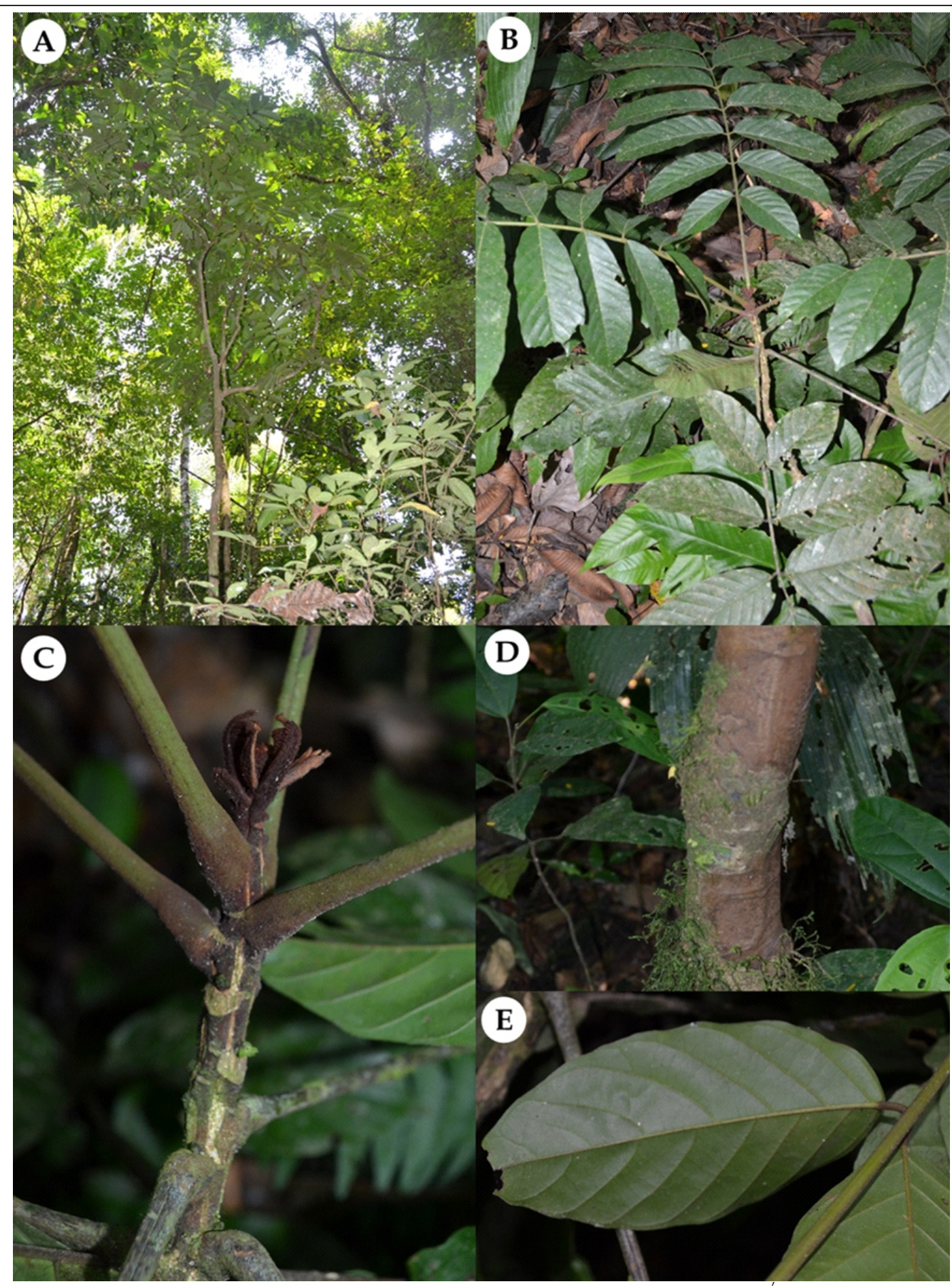

Figura 8. Tachigali sp. 1. A. Habito (individuo juvenil), B. Ramas y hojas \& C. Ápice y primórdios foliares, D. Tronco \& E. Foliolo. 


\section{Tachigali sp. 1.}

Diagnosis. Árbol hasta $30 \mathrm{~m}$; tronco irregular con epidermis blanco grisácea; ramas en teretes, tomentulosas. Sin estipulas, solo primordios apicales marrón rojizas. Hojas hasta $90 \mathrm{~cm}$ de largo; raquis terete semi-sulcado; domacio ausente. Foliolos 6-7 pares, oblongo ovados, base equilátera decurrente, obtusa, haz glabro, envés escabroso; venas secundarias bien marcadas en el envés, pero si presenta hormigas. Inflorescencias nuevas en panículas, tomentulosas seríceas. Flores y frutos no observados (Figura 8).

Discusión. Esta especie es aun no conocida, posiblemente corresponda a una especie nueva, datos más minuciosos indicaran su identidad. Pero de las descripciones actuales no comparte proximidad con ninguna de las especies descritas en la región cusqueña, tiene mayor afinidad a T. alba, especie frecuente de tierra firme en el noroeste de Brasil en los estados amazónicos de Pará y Amazonas.

Ecología. Se conoce solo de la colección única en la localidad del Pongo de Qoñec de colectada en una parcela de monitoreo permanente, esta zona se ubica en el límite con el departamento de Madre de Dios. Habita en bosques de suelos ricos, asociados a pendientes moderadas. Datos de fructificación y floración aún no se conocen.

Conservación y Usos. Localmente es conocida como "yana inkapacay". Es aprovechada ocasionalmente en el comercio maderero. No está incluida en ninguna categoría de amenaza-protección en la región del Cusco y el Perú. Se propone categorizarla como vulnerable (VU) para la región del Cusco y el Perú debido a la presencia de escasos individuos.
Material analizado. Cusco, Prov. Paucartambo, Dist. Kosñipata, Pongo de Qoñec-parcela PQO-2, 27 Agosto 2016, 550 m, 19L 214683.05 8536867.14, I. Huamantupa \&D. Huaman 19519 (CUZ).

\section{Tachigali sp. 2.}

Diagnosis. Árbol hasta $25 \mathrm{~m}$; tronco irregular con epidermis blanco rojiza; ramas en teretes, densamente tomentosas y tomentulosas con pelos marrón rojizos. Estipulas foliosos con 3 a 4 lóbulos. Hojas hasta $70 \mathrm{~cm}$ de largo; raquis terete sulcado; domacio ausente pero si presenta hormigas; foliolos 7-9 pares, oblongo elípticos, lanceolados, base equilátera, decurrente, semicordada, haz escabroso, envés tomentuloso con pelos desarrollados; venas secundarias impresas en el haz, marcadas en el envés., Inflorescencias en panículas terminales y axilares, densamente tomentulosas. Flores sésiles; sépalos lineares, 1-1.3 $\times 3-3.2 \mathrm{~mm}$, fuertemente tomentosos en la base; mismo tamaño. Frutos no observados (Figura 9).

Discusión. Esta especie es perteneciente al complejo de T. setifera, la que se diferencia notoriamente de Tachigali sp. 2 por la presencia de inflorescencias terminales largas, flores subpediceladas, de mayor tamaño (hasta $6 \mathrm{~mm}$ de largo), estambres heteromorfos y habita bosques amazónicos húmedos de tierras bajas. La descripción detallada de Tachigali sp. 2 aparentemente corresponde a una especie nueva.

Ecología. Se conoce de dos colecciones fértiles de bosques de pie de monte o premontanos a los 1350 msnm en la localidad de San Pedro (Kosñipata) y la otra de la reserva del Amarakaeri en Madre de Dios a 1050 msnm. 
Ambas localidades se encuentran relativamente próximas. Se observaron poblaciones de esta especie a partir de los 900 msnm, hasta los $1350 \mathrm{msnm}$, al parecer solo en este rango se ubican. Los periodos de floración se dan en diciembre a marzo y fructificación son desconocidos.

Conservación y Usos. Localmente es conocida como "inkapacay". La maderera es aprovechada ocasionalmente en el comercio. Se propone incluir en la categoría de vulnerable (VU) para la región del Cusco, por la presencia de pocos individuos de las poblaciones evaluadas.

Material analizado. Cusco, Prov. Paucartambo, Dist. Kosñipata, Santa Alicia, 18 Agosto 2016, 1204 m, 19L 225682 8557183, I. Huamantupa \& M.Luza 19493 (CUZ).

\section{Tachigali sp. 3.}

Diagnosis. Árbol hasta $30 \mathrm{~m}$; tronco irregular con epidermis rojiza hasta $180 \mathrm{~cm}$ de DAP; ramas en teretes, densamente tomentosas-tomentulosas con pelos marrón rojizos. Estipulas foliosas con 2 a 3 lóbulos, lóbulo mayor cerca $3 \times 5 \mathrm{~cm}$, en algunas adultas con pedicelo largo de hasta $15 \mathrm{~cm}$ de largo. Hojas hasta $80 \mathrm{~cm}$ de largo; raquis terete fuertemente sulcado; domacio vestigial presente en el raquis; foliolos 7-9 pares, oblongo elípticos, base inequilátera decurrente, haz glabro, envés escabroso; venas secundarias impresas en el haz, marcadas en el envés. Inflorescencias en panículas terminales, pedicelo marcadamente estipulaceo. Flores no observadas. Frutos 1-2.5 × 3.5-10 cm, elípticos, exocarpo negro (Figura 10).
Discusión. Esta especie es parecida a $T$. inconspicua, recientemente descrita por van der Werff (2008), pero difiere de Tachigali sp. 3 porque no presenta domacio y las estipulas foliáceas con menos desarrolladas y no pediceladas. La descripción detallada de ejemplares con flores seguramente delimitara bien la identidad de esta especie.

Ecología. Se conoce de tres colecciones en frutos de las localidades de Atalaya, límite con el departamento de Madre de Dios, donde se observaron algunas poblaciones. Habita suelos de tierra firme a los 350-450 msnm, está asociado a suelos relativamente ricos. El periodo de floración se da desde diciembre a abril y fructificación de marzo hasta agosto.

Conservación y Usos. Localmente es conocida como "pacapacay". Es aprovechada en el comercio de maderera ya que llegan a ser indiviusos de buen porte y grosor. Se propone incluir en la categoría casi amenazada (NT) por la escasa presencia de poblaciones y su distribución restricta a los límites de la región del Cusco y Madre de Dios.

Material analizado. Cusco, Prov. Paucartambo, Dist. Kosñipata. Atalaya, 18 Agosto 2016, 520 m, 19L 244836 8573099, I. Huamantupa \& M. Luza, 19436 (CUZ); Prov. La Convención, Dist. Echarati, Armihuari, 535 m, $11^{\circ} 51^{\prime} 88^{\prime \prime S ~} 072^{\circ} 466^{\prime} 69^{\prime \prime W}$, P. Nuñez et al. 19841 (CUZ). 


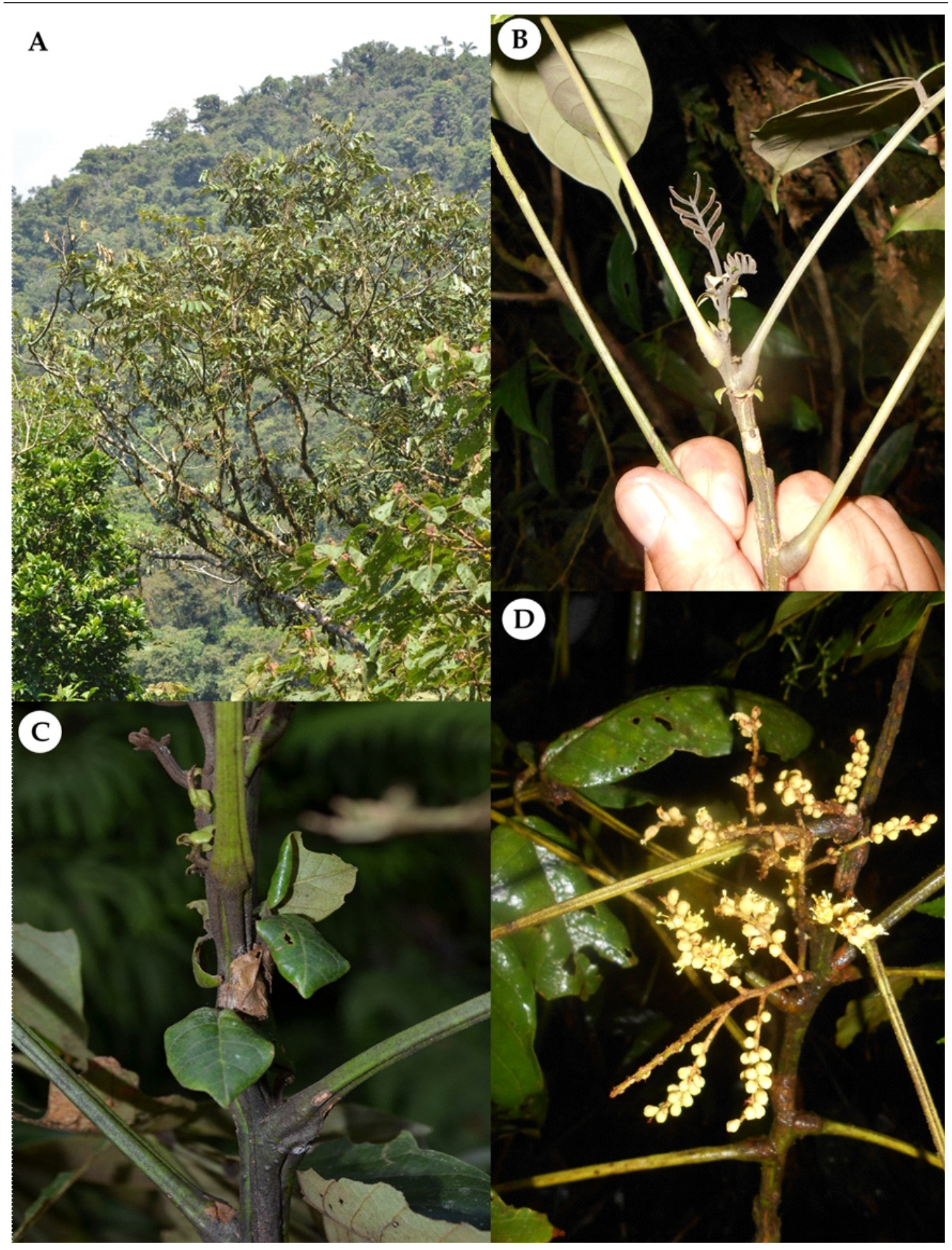

Figura 9. Tachigali sp. 2. A. Habito, B. Primordios foliares, C. Estipulas foliáceas \& D. Inflorescencias mostrando flores sésiles. 




Figura 10. Tachigali sp. 3, A. Habito, B. Tronco y raíz, C. Domacio en el raquis foliar, D. Estipulas pediceladas, E. Ramas \& F. Frutos. 


\section{Agradecimientos}

A la bolsa Capes del gobierno brasilero por el apoyo y manutención brindada durante el desarrollo del presente programa doctoral (2016-2020). A Msc. Fructuosa de la torre, directora del herbario CUZ de la UNSAAC, por las facilidades brindadas en el acceso este acervo. Al herbario RB, del Jardím Botánico de Rio de Janeiro-Brasil, donde se accedió a las colecciones para su revisión. A Gloria Calatayud, Bylli J. Jordan, Lucy Vargas, Juan Tito y Flor Zamora, por su apoyo en las colecciones en campo. Al Sr. Isaac Huamantupa, por su valioso apoyo en campo durante los muestreos en el Pongo de Qoñec.

\section{Literatura citada}

Aublet, J. B. 1775. Histoire des Plantes de la Guiane Françoise 1: 372-374, pl. 143, f.1.

Aragon, I. \& Chuspe, M. 2013. Ecología Geográfica del Cusco. Las ecorregiones, Pisos Ecológicos y sistemas ecológicos terrestres del Cusco. Gobierno Regional del Cusco. Pp. 89.

Barneby, R. C. 1996. Neotropical Fabales at NY: asides and oversights. Brittonia 48 : 174-187.

Chomicki, G.,Ward, P. S. \& Renner, S. S. 2015. The macroevolutionary assembly of ant/plant symbioses: Pseudomyrmex ants and their ant-housing plants in the Neotropics. Proceedings of the Royal Society B 282 (1819).

Ducke,A. 1922. Plantes nouvelles ou peu connues de la region amazonienne. II. Arch. Jard. Bot. Rio de Janeiro 3: 1-269.

Ducke, A. 1935. Plantes nouvelles ou peu connues de la region amazonienne. VIII. Arq. Inst. Biol.Veg. 2: 27-72.

Dwyer, J. D. 1954. The tropical American genus Tachigali Aubl. (Caesalpiniaceae). Ann. Missouri Bot. Gard. 41:223-260.

Dwyer, J. D. 1957. The tropical American genus Sclerolobium Vogel (Caesalpiniaceae)-
-Lloydia 20: 67-117.

Font Quer, P. 1982. Diccionario de Botánica. $8^{\mathrm{a}}$ reimpresión. Barcelona: Editorial Labor, S. A. 84-335-5804-8.

Forget, P.M., Kitajima, K. \& Foster, R.B. 1999. Pre- and post-dispersal seed predation in Tachigali versicolor (Caesalpiniaceae): effects of timing of fruiting and variation among trees. Journal of Tropical Ecology 15: 61-81.

Foster, B. 1977. Tachigali versicolor is a suicidal neotropical tree. Nature 268: 624-626.

Huamantupa, I. 2011. Árboles con uso maderero en el bosque tropical estacionalmente seco de la cuenca media del Urubamba, provincia de La Convención Cusco. Revista Queuña 4: 29-37.

INEI 2014. Departamento Cusco. Instituto nacional de estadistica e informatica. Registro nacional de identificacion y estado civil. Consultado el 26 de mayo de 2016.

IUCN 2014. Guidelines for using the IUCN red list Categories and Criteria, version 11. Prepared by the Standards and Petitions Subcommittee. A v a i l a b l e f r o m : http://www.iucnredlist.org/documents / redlistGuidelines.pdf (accessed 10 November 2016).

Josse C., Cuesta F., Navarro G., Barrena V., Cabrera E., Chacón-Moreno E., Ferreira W., Peralvo M., Saito J. \& Tovar A. 2009. Ecosistemas de los Andes del Norte y Centro. Bolivia, Colombia, Ecuador, Perú y Venezuela. Secretaría General de la Comunidad Andina, Programa Regional ECOBONAIntercooperation, CONDESAN Proyecto Páramo Andino, Programa BioAndes, EcoCiencia, NatureServe, IAvH, LTAUNALM, ICAEULA, CDC-UNALM, RUMBOL SRL. Lima, Perú.

Lewis, G. P. 2005. Tribe Caesalpinieae. Pp. 127-161. In: G. Lewis, B. Schrire, B. Mackinder \& M. Lock (editors). Legumes of the world. Royal Botanic Gardens, Kew. 
Moulin, L., Munive, A., Dreyfus, B., y Bolvin-Masson, C. 2001. Nodulation of legumes by members of the $b$ sub-class of Proteobacteria. Nature 411: 948-950.

Pennington, R. T., Lavin, M. \& OliveiraFilho, A. 2009. Woody plant diversity, evolution, and ecology in the tropics: perspectives from seasonally dry tropical forests. Annual Review of Ecology, Evolution, and Systematics 40: 437-457.

Pipoly, J.J. 1995. A new Tachigali (Fabaceae: Caesalpinioideae) from western Amazonia. Sida 16:407-411.

Poorter, L., Zuidema, P. A., Pena-Claros, M. \& Boot, R. G.A. 2005. A monocarpic tree species in a polycarpic world: how can Tachigali vasquezii maintain itself so successfully in a tropical rain forest community? Journal of Ecology 93: 268-278.

Silva, L. F. G. \& Lima, H. C. 2007. Mudanças nomenclaturais no gênero Tachigali Aubl. (Leguminosae-Caesalpinioideae) no Brasil. Rodriguesia 58: 397-401.

Silva, L. F. G., Cardoso, J. T, L., Cardoso, D. B. O. S. \& Lima, H. C. 2016. Tachigali spathulipetala, a new threatened caesalpinioid tree species (Leguminosae) from the Brazilian Atlantic Forest. Systematic Botany 41(4): 971-976.

Van Der Werff, H. 2008. A synopsis of the genus Tachigali (Leguminosae: Caesalpinioideae) in northern South America. Ann. Missouri Bot. Gard. 95: 618-660.

Zarucchi, J. \& Herendeen, P. 1993. Tachigali (Fabaceae). v. 45. Pp. 1.254-1.255. In: L. Brako \& J. Zarucchi (eds.). Catalogue of the flowering plants and gymnosperms of Peru. Monographs in Systematic Botany from the Missouri Botanical Garden. Missouri Botanical Garden, St. Louis.

\section{Páginas web}

Outlook on climate change adaptation in the Tropical Andes mountains. Available from: https: / /www.researchgate.net/publication/3028 81486 Outlook on climate change adaptation in the_Tropical_Andes_mountains\#pag:26:mr ect: $(350.09,110.70,128.97,13.49)$ [accessed Oct 9, 2016].

Missouri Botanical Garden, Plant Science Tropicos.

http: / / mobot.mobot.org

Field Museum.

http: / / fieldmuseum.org

The plant list.

http: / / www.theplantlist.org. 